\title{
The original vaccine
}

\section{Michael Bennett: War against smallpox. Edward Jenner and the global spread of vaccination. Cambridge: Cambridge University Press, 2020, $\mathrm{xii}+424$ pp, $£ 29.99$ PB}

\section{Stuart Blume ${ }^{1}$}

Accepted: 23 February 2021 / Published online: 11 March 2021

(c) The Author(s), under exclusive licence to Springer Nature B.V. 2021

Whilst starting to read this book, I enumerated for myself the things I knew about smallpox. They didn't amount to more than a few facts, familiar to anyone with the slightest interest in the history of medicine. I knew of Lady Mary Wortley Montagu who had witnessed smallpox inoculation in the Ottoman Empire and had introduced it to London society. I had heard of Farmer Jesty, and of course of Edward Jenner, the medical practitioner from Gloucestershire, who, later in the eighteenth century, demonstrated the prophylactic benefits of inoculation using cowpox. I knew that it was this bovine association to which we owe the terms 'vaccine' and 'vaccination'. I'd heard of the Royal and Philanthropic Expedition which took vaccine to Spain's smallpox-ravaged colonies at the start of the nineteenth century. Then, chronologically speaking, a blank space opens up in my knowledge of smallpox. It lasts until the 1970s and the global eradication campaign. In 1980, the World Health Organization (WHO) declared smallpox to have been eradicated globally.

For anyone interested in the recent history of international health (or global health, its modern mutation), or in its growing reliance on vaccination, the last of my little library of facts are of key significance. The others are more like anecdotes, to be deployed sparingly in the interests of a little historical flavouring. By contrast, the politicking which led up to the resolution committing the WHO to smallpox eradication, the collaboration across the Cold War divide which followed, and the lessons which were drawn from its success, continue to engage historians' attention. And rightly so. The effective functioning of the smallpox campaign inspired what became the Expanded Programme of Immunization (EPI). Thanks to adoption of the EPI by country after country countless lives have been saved across the globe. More problematically, the smallpox campaign inspired an almost religious devotion to the idea of eradication among a handful of influential public health officials. 'We need to eradicate something else! Measles perhaps. Or polio. What precisely we go for

Stuart Blume

s.s.blume@uva.nl

1 Department of Anthropology, University of Amsterdam, Amsterdam, Netherlands 
matters less'. Despite the WHO's then Director-General (Halfdan Mahler) emphasizing that this was not the lesson to be drawn, it was. The result was the Global Polio Eradication Initiative (GPEI), established in 1987 and with an eradication target date of 2000. That proved unattainable. The GPEI is still running, planning currently until 2023. It is likely to be pushed back further now the Covid-19 pandemic has disrupted so many routine vaccination programmes.

The current pandemic has also led to unprecedented media attention for vaccines and vaccination. What should we make of current 'vaccine nationalism', pitting country against country in the race to develop a vaccine, and in successfully competing for limited supplies? The contrast with the smallpox eradication initiative of the 1970s is striking. How had the USA and the Soviet Union collaborated so effectively at the height of the Cold War?

These are among the kind of issues which engage the historians whose work I read and use. Their analyses tend to draw extensively on the social sciencesanthropology, political science, sociology, science and technology studies. The book under review is a very different kind of book. But then its author is a very different kind of historian.

Michael Bennett, Emeritus Professor of History at the University of Tasmania, is a medieval historian: author of a number of books on late medieval England. Unsurprisingly, his study of 'the global spread of vaccination' is not an outgrowth of his previous work. More a labour of love. It seems to have been conceived, nearly two decades ago, whilst its author was browsing in second-hand bookstores and openaccess libraries. Perhaps he is justified in labelling these 'cultural spaces now almost of another era'. Perhaps academic managers ceased regarding browsing an acceptable use of time, even before libraries and bookstores became physically inaccessible for many of us. Perhaps, as Professor Bennett hints, something has been lost. But though intriguing, these are not the topics of his book.

Before continuing, I must confess that I know very little medieval history and even less of medieval historians' discursive styles. This is surely why I found the style in which this book is written unfamiliar: the result, I imagine, of its transposition from a field of research with very different conventions.

With the help of various assistants and graduate students Professor Bennett has drawn on sources in an astonishing range of languages: Dutch, German, Lithuanian, Polish, Russian, Spanish, and Swedish. Whilst an awe-inspiring achievement, this also gives the book a somewhat encyclopaedic character. To be sure, both the range of sources and the character of the book reflect what the author set out to do: to provide a detailed cartography of the global spread of Jennerian vaccination. Globalization avant la lettre. A cartography, moreover, embellished with countless curious facts. I was surprised and delighted to learn that Jenner was elected a Fellow of the Royal Society on the basis of his study of the nesting habits of the cuckoo!

Most of what is discussed in the book's 14 chapters took place in the years around 1800. The first three are devoted to the history of the disease, to early prophylactic practices such as the variolation which Lady Mary Montagu had seen in Istanbul, and to Jenner's demonstration that inoculation with cowpox was a far safer alternative. In 1798, he published his Inquiry into the Variolae vaccinae known as the Cow Pox. Despite Napoleon's conquest of much of Europe, and his plans for the invasion of England, Jenner's work soon became widely known, his Inquiry translated into French and 
other languages. In a section entitled 'Doctors without Borders', Bennett describes the frustrations of medical practitioners who had learned of Jenner's work, were enthusiastic to try out the procedure, but had difficulties in obtaining samples of vaccine. Few were in a position to draw matter from infected cows. Diffusion of the practice, as distinct from knowledge of it, depended on finding ways of transporting potent vaccine. One way was through its absorption on a cotton thread and then drying it. Frequently samples arriving at their destination were found to have lost their potency. Clearly, the challenge involved in providing vaccine to distant colonies was all the greater. That such undertakings often succeeded depended on medical networks, relaying the vaccine in stages. At each stage, sometimes onboard ship, the dried vaccine would be inoculated, and after a short while a sample of fresh 'lymph' taken from the person so treated. This in turn could be dried and taken further.

Successive chapters of the book follow the movement of smallpox vaccination to Northern Europe (Chapter 7), across the Pyrenees to Spain and Portugal (Chapter 8), to the Russian Empire (Chapter 9), South Asia (Chapter 10), North America (Chapter 11), Latin America (Chapter 12), and Oceania (Chapter 13). Each destination is treated in great detail, drawing on local sources, and embellished by numerous anecdotes. In more than 150 pages, we follow the vaccine through France, into Germany, the Netherlands and Scandinavia (in Chapter 7), and to its arrival in Cape Colony (in Chapter 13).

Chapter 9, for example, begins with knowledge of Jenner's discovery arriving in St Petersburg in 1799. A sample of vaccine arrived in the city in 1800 but was found to be inert. Under the patronage of the Dowager Empress Maria Fedorovna, a physician in Breslau (now Wrocław) then sent samples to the Imperial Court. This had moved to Moscow, and it took the sample 18 days to arrive. 'Leading medical men from across Russia were on hand to witness the successful vaccination of Anton Petrov who, in commemoration of the event, was renamed Vaktsinov' (223). By the spring of 1802, plans to make the new prophylaxis available throughout the Russian Empire were in hand. What was planned involved not the transportation of dried vaccine, but an expedition of vaccinated children who would be used to vaccinate local children. Directed by an Imperial ukase, the expedition set out from St Petersburg in June 1802 and began by vaccinating 47 children in Novgorod (232).

The extensive detail and the embellishments of every chapter result in something approaching a work of reference. Though the historian of modern medicine will not immediately find exemplifications of familiar themes, the book certainly merits its place in the library. It might appropriately be placed alongside Fenner et al.'s magisterial account in Smallpox and its Eradication (Fenner et al. 1988).

\section{Reference}

Fenner, Frank, Donald A. Henderson, Isao Arita, Zdenek Jezek, Ivan Danilovich Ladnyi, et al. 1988. Smallpox and its Eradication. Geneva: World Health Organization.

Publisher's Note Springer Nature remains neutral with regard to jurisdictional claims in published maps and institutional affiliations. 